\title{
COMPARATIVE STUDIES ON THE GROWTH AND REPRODUCTIVE PERFORMANCES OF RHODNIUS PROLIXUS REARED ON DIFFERENT BLOOD SOURCES
}

\author{
JOSÉ EUGENIO P. LIMA GOMES; P. AZAMBUJA* \& E. S. GARCIA
}

\begin{abstract}
Instituto Oswaldo Cruz, Departamento de Bioquímica e Biologia Molecular, Caixa Postal 926, 20001, Rio de Janeiro, RJ, Brasil *Departamento de Biologia Geral, Universidade Federal Fluminense, Niterói, RJ, Brasil
\end{abstract}

\begin{abstract}
Host blood source was found to affect both the development and the reproductive performance of Rhodnius prolixus. The insects were reared on citrated human, rabbit, chicken, sheep and horse blood sources, through a membrane feeder, during an entire life cycle, from eggs to adults. Development and reproduction in terms of the number of unfed insects, number of moulting, mortality intermoulting period, number of egg/female, conversion of blood into egg ( $\mathrm{mg}$ meal/egg) and percentage of hatch as effective physilogical parameters were investigated. Our results showed that human or rabbit blood meals were more nutritionally efficient than the other blood samples used because (i) the insects developed faster, presented low mortality and about $80 \%$ of them reached the adult stage; and (ii) females oviposited an average of at least $100 \%$ more eggs. The inefficiency of chicken and horse blood sources as diets for $\mathrm{R}$. prolixus was manisfested in (i) a decrease of the amount of ingested blood and (ii) only a reasonable nutritional quality. The inadequacy of sheep blood was observed by a mortality extremely high, poor moulting response and drastic reduction in egg production.
\end{abstract}

Key words: Rhodnius prolixus -- development - reproduction

The blood-sucking bug Rhodnius prolixus and other triatomines have been reared and maintained successfully in the laboratory for many years (for review see Núñez \& Segura, 1987 ). Presently, the mass-rearing of $R$. prolixus is largely dependent on the availability of a suitable source of blood for the insect. Many workers described the use of either living animals such as rabbits, sheep or chicken as hosts (Buxton, 1930; Correa, 1954; Ryckman \& Ryckman, 1967; Gardiner \& Maddrell, 1972; Hill \& Campbell, 1975) or the presentation of blood through appropiate types of membranes (Gardiner \& Maddrell, 1972; McGuire et al., 1973; Garcia et al., 1975a, b; 1984; Pimley \& Pimley, 1978). Moreover, Gardiner \& Maddrell (1972) fed all larval instars of $R$. prolixus through artificial membranes on defibrinated sheep blood. However, deleterious effects of this blood showed a mortality unacceptably

This work was supported by the UNDP/World Bank/ WHO Special Programme for Research and Training in Tropical Diseascs and by FINEP and CNPq.

Received 19 March 1990.

Accepted 8 May 1990. high, and a poor moulting response in 5 th-instar. Differently, McGuire et al. (1973) pointed out that Rhodnius can be reared from generation to generation using a diet of heparinised human blood. Additionally, Pimley \& Langley (1978) described the success of rearing $R$. prolixus for three generations on a diet of defibrinated pig blood fed through membrane. Recently, it has been reported that in adult females of $R$. prolixus the autogeny and egg production are dependent on the blood source. For example, a colony fed on human blood presents a reproductive capacity higher as compared to that of insects fed on sheep blood (Valle et al., 1987). The latter insects presented autogeny whereas the insects fed blood on sheep did not.

Nevertheles, in spire of these scattered data, only few comparative studies have been conducted to determine whether or not $R$. prolixus can be mantained on different blood sources with the same efficiency. If the insect could be successfully maintained on membrane feeding techniques, studies on the effect of different blood meal sources could be investigated, especially for large-scale rearing and nutritional requirements of this insect. 
TABLE I

Development, rejcction to feed and mortality of Rhodnius prolixus reared from 1 st- to 5 th-instar larvae on different feeding sources

\begin{tabular}{|c|c|c|c|c|c|c|c|c|}
\hline \multirow{2}{*}{ Instar-larvae } & \multirow{2}{*}{$\begin{array}{l}\text { Blood } \\
\text { source }\end{array}$} & \multirow{2}{*}{$\begin{array}{c}\text { Number of } \\
\text { insects }\end{array}$} & \multicolumn{2}{|c|}{$\begin{array}{l}\text { Number of } \\
\text { unfed insects }\end{array}$} & \multicolumn{2}{|c|}{$\begin{array}{l}\text { Number of } \\
\text { moulting }\end{array}$} & \multirow{2}{*}{\multicolumn{2}{|c|}{$\begin{array}{l}\text { Mortality } \\
(\mathrm{n}) \quad(\%)\end{array}$}} \\
\hline & & & (n) & $(\%)$ & (n) & (\%) & & \\
\hline \multirow{5}{*}{1 st- } & Human & 200 & 15 & 7.5 & 183 & 99 & 2 & 1.0 \\
\hline & Rabbit & 200 & 10 & 5.0 & 188 & 99 & 2 & 1.0 \\
\hline & Chicken & 200 & 10 & 5.0 & 187 & 98 & 3 & 1.5 \\
\hline & Sheep & 200 & 5 & 2.5 & 121 & 63 & 5 & 2.5 \\
\hline & Horse & 200 & 45 & 25.0 & 155 & 77 & 3 & 1.5 \\
\hline \multirow{5}{*}{ 2nd- } & Human & 183 & 3 & 1.6 & 178 & 99 & 2 & 1.1 \\
\hline & Rabbit & 188 & 6 & 3.1 & 179 & 98 & 3 & 1.6 \\
\hline & Chicken & 187 & 6 & 3.2 & 178 & 98 & 3 & 1.6 \\
\hline & Sheep & 121 & 6 & 4.9 & 72 & 63 & 9 & 7.8 \\
\hline & Horse & 155 & 22 & 16.0 & 105 & 88 & 6 & 5.0 \\
\hline \multirow{5}{*}{ 3rd- } & Human & 178 & 7 & 3.9 & 170 & 99 & 1 & 0.5 \\
\hline & Rabbit & 179 & 7 & 3.9 & 169 & 98 & 3 & 1.7 \\
\hline & Chicken & 178 & 8 & 4.4 & 163 & 96 & 3 & 1.7 \\
\hline & Sheep & 72 & 7 & 9.7 & 42 & 65 & 12 & 18.4 \\
\hline & Horse & 105 & 27 & 25.7 & 66 & 84 & 8 & 10.2 \\
\hline \multirow{5}{*}{4 th- } & Human & 170 & 5 & 2.9 & 165 & 100 & 0 & 0 \\
\hline & Rabbit & 169 & 5 & 2.9 & 164 & 100 & 0 & 0 \\
\hline & Chicken & 163 & 3 & 1.8 & 145 & 91 & 2 & 1.2 \\
\hline & Sheep & 42 & 3 & 7.1 & 22 & 56 & 15 & 35.7 \\
\hline & Horse & 66 & 12 & 18.1 & 21 & 76 & 8 & 14.8 \\
\hline \multirow{5}{*}{5 th- } & Human & 165 & 6 & 3.6 & 159 & 100 & 0 & 0 \\
\hline & Rabbit & 164 & 7 & 4.2 & 157 & 100 & 0 & 0 \\
\hline & Chicken & 145 & 6 & 4.1 & 96 & 69 & 4 & 2.8 \\
\hline & Sheep & 22 & 1 & 4.5 & 5 & 25 & 10 & 47.6 \\
\hline & Horse & 41 & 10 & 24.3 & 16 & 52 & 6 & 19.3 \\
\hline
\end{tabular}

To show that the efficiency or reluctance to feed on a given blood meal is not due to the animal but rather to the palatability and nutritional value of the blood, we described herein the results of feeding, through a membrane feeder, using distinct blood source for $R$. prolixus during an entire life cycle, from eggs to adults. Comparison on the differences in engorgement, moulting period of time, numbers of moulting, egg production or in the efficiency of ingested blood conversion into eggs in insects fed on different blood sources may indicate the blood utilization and explain the variable fecundity and development of this insect when fed on different blood meal sources. Information about such changes may be useful for laboratories that apply $R$. prolixus as an insect model for studying biochemistry, physiology and control of triatomine vectors.

\section{MATERIALS AND METHODS}

Insects - Newly emerged first-instar larvae of $R$. prolixus used in these studies were obtained from a colony routinely maintained at our laboratory since 1965 using citrated human blood. Details of the standard rearing condition at $28^{\circ} \mathrm{C}$ and handling procedures have been previously described (Garcia et al., 1975a, b; 1984).

Blood sources - Citrated blood samples from human, rabbit, chicken, sheep and horse were prepared as previously described (Garcia et al., 1984) and maintained for few hours at $5^{\circ} \mathrm{C}$ were used throughout the experiments.

Experimental protocol - Five experimental groups (A-E) were formed out of 200 1st-instar 
TABLE II

Comparative effects of different feeding sources on the body weight, intake of ingested blood and intermoult period between feeding to ecdysis of all instar larvae of Rhodnitus prolixus

\begin{tabular}{|c|c|c|c|c|c|}
\hline \multirow{2}{*}{ Instar-larvae } & \multirow{2}{*}{ Blood source } & \multirow{2}{*}{$\begin{array}{l}\text { Body weights } \\
\text { (mg) }\end{array}$} & \multirow{2}{*}{$\begin{array}{l}\text { Ingested blood } \\
(\mathrm{mg})\end{array}$} & \multicolumn{2}{|c|}{$\begin{array}{l}\text { Intermoult period } \\
\text { (range in days) }\end{array}$} \\
\hline & & & & after feeding & $\begin{array}{l}\text { after hatching } \\
\text { (cumulative) }\end{array}$ \\
\hline \multirow{5}{*}{ l st- } & Human & $0.45 \pm 0.04$ & $3.5 \pm 0.32$ & $8-12$ & $18-22$ \\
\hline & Rabbit & $0.45 \pm 0.04$ & $4.6 \pm 0.38$ & $7-10$ & $17-20$ \\
\hline & Chicken & $0.45 \pm 0.04$ & $3.9 \pm 0.36$ & $8-12$ & $18-22$ \\
\hline & Sheep & $0.45 \pm 0.04$ & $4.0 \pm 0.42$ & $15-18$ & $25-29$ \\
\hline & Horse & $0.45 \pm 0.04$ & $3.4 \pm 0.38$ & $12-15$ & $22-25$ \\
\hline \multirow{5}{*}{ 2nd- } & Human & $1.80 \pm 0.15$ & $8.2 \pm 0.72$ & $10-12$ & $42-44$ \\
\hline & Rabbit & $1.30 \pm 0.16$ & $13.5 \pm 1.40$ & $10-14$ & $40-44$ \\
\hline & Chicken & $1.40 \pm 0.16$ & $11.1 \pm 1.06$ & $11-15$ & $43-47$ \\
\hline & Sheep & $1.20 \pm 0.13$ & $10.9 \pm 0.97$ & $14-20$ & $53-59$ \\
\hline & Horse & $1.75 \pm 0.19$ & $6.1 \pm 0.75$ & $12-19$ & $47-54$ \\
\hline \multirow{5}{*}{3 rd- } & Human & $4.55 \pm 0.38$ & $33.7 \pm 0.45$ & $12-16$ & $66-70$ \\
\hline & Rabbit & $5.25 \pm 0.48$ & $35.3 \pm 0.40$ & $11-16$ & $65-70$ \\
\hline & Chicken & $4.90 \pm 0.42$ & $21.8 \pm 0.27$ & $14-22$ & $71-79$ \\
\hline & Sheep & $4.05 \pm 0.39$ & $31.0 \pm 0.37$ & $15-25$ & $84-94$ \\
\hline & Horse & $3.95 \pm 0.45$ & $14.0 \pm 0.22$ & $15-18$ & $79-82$ \\
\hline \multirow{5}{*}{4 th- } & Human & $12.80 \pm 1.15$ & $105.0 \pm 9.8$ & $13-17$ & $93-97$ \\
\hline & Rabbit & $13.65 \pm 1.55$ & $111.9 \pm 10.8$ & $12-14$ & $92-94$ \\
\hline & Chicken & $11.57 \pm 1.30$ & $69.0 \pm 7.9$ & $14-24$ & $103-113$ \\
\hline & Sheep & $9.25 \pm 1.25$ & $101.0 \pm 9.9$ & $16-25$ & $120-129$ \\
\hline & Horse & $8.40 \pm 0.99$ & $51.6 \pm 6.8$ & $13-25$ & $105-117$ \\
\hline \multirow{5}{*}{5 th- } & Human & $42.86 \pm 4.85$ & $257.2 \pm 19.8$ & $20-23$ & $127-130$ \\
\hline & Rabbit & $30.57 \pm 3.35$ & $273.9 \pm 25.9$ & $18-24$ & $122-128$ \\
\hline & Chicken & $32.33 \pm 3.10$ & $173.1 \pm 19.4$ & $21-30$ & $144-153$ \\
\hline & Sheep & $25.52 \pm 2.82$ & $154.5 \pm 16.9$ & $24-31$ & $163-170$ \\
\hline & Horse & $22.05 \pm 3.55$ & $118.0 \pm 15.7$ & $21-30$ & $158-167$ \\
\hline
\end{tabular}

larvae each, and then allowed to feed 10 days after hatching, on either human (A), rabbit (B), chicken (C), sheep (D) and horse blood (E). We then followed the development of these groups until the imaginal stage. Larvae from the 2nd. to 5 th-instar as well as adult individuals were allowed to feed on the respective blood meals each 10 days after the last moulting of each instar of development. The insects were allowed to feed on a membrane feeder apparatus (Garcia et al., 1984) for $30 \mathrm{~min}$, after which the feeding response (number of bugs engorged) was recorded. The insects were weighed before and immediately after feeding and the intake of meal ingested was estimated by subtraction. Any bugs which fed less than one third of the blood weight ingested by fully gorged insects were rejected and those that did not undergo ecdysis during 10 days after the last moulting of their groups were removed and discarded. The adult females were mated, the eggs produced collected, and the percentage hatch were recorded for each experimental group. Any dead insects were removed and their number recorded.

\section{RESULTS AND DISCUSSION}

Blood meal source and larval development In a typical experiment we followed the development of the five experimental groups of insects from the 1st-instar larvae to adult stage (Table I). As can be seen of the 2001 st-instar larvae of each group, $159(79.5 \%), 157(77.0 \%)$, $96(48.0 \%), 5(2.5 \%)$ and $16(8.0 \%)$ insects, for human, rabbit, chicken, sheep and horse blood meals, respectively, reached the adult stage. 
The small number of moulting in the group fed on sheep and horse blood was observed from the 2 nd-instar to adult stage. Horse blood meal also presented the higher percentage of meal rejection. A significant mortality rate occurred among the insects of these two latter groups from the 2nd-instar larvae to adult stage but the mortality for bugs reared on sheep blood was about 50\% higher than the group fed on horse blood. The groups fed on human, rabbit and chicken blood meals presented only background mortality (Table I).

Table II shows that insects fed on human and rabbit blood meals always presented shorter intermoult periods during the entire life cycle than the other groups reared on chicken, sheep and horse blood. The last three groups experienced a progressive ecdysis delayed during the evolution of the developmental cycle when compared with insects of the other two groups. The 5th-instar larvae of the groups fed on chicken, sheep and horse blood meals, for example, had very protracted intermoult period that extended from 21 even to 31 days after feeding, whereas insects of the group reared on human and rabbit blood meals underwent moulting in a period of 18.24 days.

The results on the body weights of the different instars together with the blood meal intakes are also demonstrated in Table II clearly showing that the mean blood meal sizes were reduced in the groups fed on chicken, sheep or horse blood.

Finally, under our experimental conditions the entire life cycle from the eclosion of eggs to adult stage ranged of $127-130,122-128$, 144-153, 163-170 and 158-167 days, respectively, for insects reared on human, rabbit, chicken, sheep and horse blood meals (Table II).

The results on the development of the larval instar reared with human or rabbit blood meals were very similar to those data obtained on Rhodnius fed on living hosts (Buxton, 1930; Gardiner \& Maddrell, 1972) or reared on membrane feeder with rabbit or pig blood samples (Baines, 1956; Lake \& Friend, 1968; Pimley \& Langley, 1978).

Adult feeding and egg production - Table III shows the body weights of adult females
$R$. prolixus, blood meal intakes, number of eggs produced, percentage of eclosion and conversion of $\mathrm{mg}$ of blood ingested to eggs, during two oviposition cycle, i.e., two feeding as adults.

Distinct diets differently changed adult female body weights. Insects reared on chicken, sheep and horse blood meals were $78.1-79.6 \%$, $61.8-63.0 \%$ and $53.0-54.0 \%$ of the size of females reared on rabbit and human blood meals in the two reproductive cycles (Table III). They were weighed at 10 days postmoulting, when proportional differences remained the same. Since adult females fed on human and rabbit blood meals were larger than those reared on chicken, sheep and horse blood meals, they took heavier blood meals as adults and laid more eggs. However, the most interesting aspect of Table III is that the blood amount associated with the production of one egg is fairly constant (ranging from 4.8 to 5.4 $\mathrm{mg}$ ingested blood/egg) in females reared on human, rabbit, chicken and horse blood meals, although females reared on chicken and horse blood meals fed approximately $55 \%$ less blood than the other two groups. However, the quantify associated with the production of one egg for females fed on sheep blood surprisingly was twice larger than their former groups following the two feeding sessions (about 10 mg ingested blood/egg) (Table III).

Besides the results detailed above we could also observe that no significant mortality occurred among the adults over a period of 20 days after feeding. Actually, the mean hatch over 15 days of egg production exceeded $97 \%$ in all experimental groups.

Take together, our results correlated differences between distinct blood meal sources with the development and reproductive performances of $R$. prolixus. They clearly indicated that human and rabbit blood meals were more efficient nutritionally than the other blood samples used mainly because (i) the insects developed faster and about $80 \%$ of them reached the adult stage; and (ii) females oviposited an average of at least $100 \%$ more eggs than the other blood sources.

The success of rearing Rhodnius on human and rabbit blood meals seems to be dependent on properties of themselves which in same way lack in chicken, sheep and horse blood meals. 


\section{TABLE HI}

Comparative effects of different feeding sources on the body weight, intake of ingested blood, number of eggs and conversion of ingested blood to eggs of adult females of Rhodnius prolixus

\begin{tabular}{|c|c|c|c|c|c|c|}
\hline $\begin{array}{l}\text { Blood } \\
\text { source }\end{array}$ & $\begin{array}{l}\text { Number of } \\
\text { females }\end{array}$ & $\begin{array}{c}\text { Body weight } \\
\text { (mg) }\end{array}$ & $\begin{array}{l}\text { Ingested blood } \\
\text { (mg) }\end{array}$ & $\begin{array}{l}\text { Number of } \\
\text { eggs/temale }\end{array}$ & $\begin{array}{c}\text { Conversion of blood } \\
\text { to eggs } \\
\text { (mg meal/egg) }\end{array}$ & $\begin{array}{l}\text { Hatch } \\
(\%)\end{array}$ \\
\hline \multicolumn{7}{|c|}{ 1st-oviposition cycle } \\
\hline Human & 80 & $55.52 \pm 6.90$ & $155.9 \pm 16.3$ & $29.5 \pm 3.7$ & 5.3 & 98 \\
\hline Rabbit & 78 & $56.67 \pm 6.05$ & $161.4 \pm 15.8$ & $30.0 \pm 3.2$ & 5.4 & 99 \\
\hline Chicken & 47 & $44.24 \pm 5.20$ & $76.6 \pm 9.8$ & $14.5 \pm 2.5$ & 5.3 & 98 \\
\hline Sheep & $20^{\mathrm{b}}$ & $35.05 \pm 4.43$ & $66.4 \pm 9.3$ & $6.4 \pm 1.2$ & 10.4 & 97 \\
\hline Horse & $20^{b}$ & $30.25 \pm 4.87$ & $72.4 \pm 9.5$ & $15.0 \pm 3.4$ & 4.8 & 100 \\
\hline \multicolumn{7}{|c|}{ 2nd-oviposition cycle } \\
\hline Human & 69 & $65.57 \pm 7.25$ & $158.6 \pm 17.6$ & $30.5 \pm 4.2$ & 5.2 & 99 \\
\hline Rabbit & 68 & $67.84 \pm 6.69$ & $169.6 \pm 16.9$ & $32.0 \pm 4.5$ & 5.3 & 98 \\
\hline Chicken & 40 & $50.05 \pm 6.05$ & $103.3 \pm 9.7$ & $19.5 \pm 2.7$ & 5.3 & 97 \\
\hline Sheep & 18 & $42.70 \pm 5.68$ & $114.5 \pm 13.9$ & $11.8 \pm 3.0$ & 9.7 & 100 \\
\hline Horsc & 19 & $36.56 \pm 4.79$ & $104.0 \pm 12.7$ & $20.0 \pm 4.1$ & 5.2 & 98 \\
\hline
\end{tabular}

a: each oviposition cycle was observed during 20 days.

$b$ : since sheep and horse blood meals produced only a small number of adults (see Table $\mathbf{I}$ ) we completed these groups of females from other experimental groups reared on the same feeding diets.

Some of these properties basing on the development and reproductive performances as well as on the intake of ingested blood were con. sidered as the nutritional quality and the palatability of the meals. The human and rabbit blood samples therefore presented an excellent nutritional value and were acceptable as regards the taste for the insects; chicken and horse blood diets had a reasonable nutritional quality but a low palatability; finally, sheep blood meal was only partially rejected by the insects but the nutritional value was very poor for $R$. prolixus. The special feeding behavior of this insect makes it an useful model to investigate nutritional and palatability parameters of blood meals to hematophagus insects.

\section{ACKNOWLEDGEMENTS}

To Dr Wilson Savino (FlOCRUZ) for suggestions and critically reviewing the manuscript.

\section{RIFIERLNCES}

BAINI:S, S., 1956. Role of symbiotic bacteria in nutrition of Rhodnius prolixus (Hemiptera). $J$. Exp. Biol., 33:535-541.

BUXTON. P. A., 1930. The bioloyy of a bloodsucking bug, Rhodnins prolixus Stal. Trans. R. Ent. Soc. lond., 78: 227-239.

CORRlA, R, R., 1954. Alguns dados sobre a criação de Triatomíneos em laboratório. Folia Clin. Biol., 22: $51-56$.

GARCIA, E. S.; AZAMBUJA, P. \& CONTRERAS, V. T., 1984. Large-seale rearing of Rhodnius proli$x u s$ and preparation of metacyclic trypomastigotes of Trypanosoma cruzi, p. 43-46. In C. M. Morel (ed.), Genes and Antigens of parasites, $A$ Laboratory Manual. Fundaçāo Oswaldo Cruz/liNtP/ $\mathrm{CNPq} / \mathrm{WHO}$.

GARCIA, E. S.; GARCIA, M. L. M.; MACARINI, J. D. \& UBATUBA, Iः B., 1975a. Alimentação de Rhodnius prolixus no laboratório. An. Acad. Brasil. Ciênc., 47:537-545.

GARCIA, E. S.: GARCIA, M. L. M.; MACARINI, J. D. \& UBATUBA, F. B., 1975b. Intluência do número de hemácias no volume de sangue sugado por larvas de Rhodnius prolixus. Rev. Bras. Biol., $35: 207-210$.

GARDINLR, B. O. C. \& MADDRtLLL, S. H. P., 1972. Techniques for routine and large-scale rearing of Rhodnius prolixus Stal (Hem., Reduviidae). Bull. ent. Res., 61: 505-515.

HILL, P. \& CAMPBELL, J. A., 1975. Improved rearing of symbiont-free and infected Rhodnits prolixus using rabbit-ear warmers and simple microbiological isolators. Laboratory Practice. 24: 746-747.

LAKE, P. \& FRIEND, W. G., 1968. The use of artificial diets to determine of the effects of Nocardia rhodnii on the development of Rhodnius prolixus. J. Insect Physiol., 14:543-562.

MACGUIRI, E. J.; HABOWSKY, J. F. J.; LLLMB, G. \& DF, LA IGLESIA, İ. A., 1973. An experimental approach to the study of drugs in invertebrate systems. I. Mass feeding of Rhodnius prolixus Stal (Hemiptera, Reduviidae). Can. J. Zool., 5I: 315-318. 
NŨNES, J. A. \& SEGURA. E. L., 1987. Rearing of Triatominae, p. 31-40. In R. R. Brenner \& A. M Stoka (eds), Chagas' Disease Vectors; Anatomic and Physiological Aspects. CRC Press, Boca Raton, Florida, USA.

PIMLEY, R. W. \& LANGLEY, P. A., 1978. Rearing triatomine bugs in the absence of a live host and some effects of diet on reproduction in Rhodnius prolixus Stal (Hemiptera, Reduviidae). Bull. ent.
Res., 68: 243-250.

RYCKMAN, R. E. \& RYCKMAN, A. E., 1967.

Reduviid bugs, p. 183-200. In C. N. Smith (ed.), Insect colonization and mass production. Academic Press, New York.

VALLE, D.; GOMES, J. E. P. L.; GOLDENBERG, S. \& GARCIA, E. S., 1987. Rhodnius prolixus vitellogenesis: dependence upon the blood source. J. Insect Physiol., 33: 249-254. 